\title{
พื) $\mathfrak{x} \mathfrak{w} \bullet \mathfrak{t} \mathfrak{l}$.
}

Durd bie Einfübrung beß neuen Bürgerlidgen Be= jeb̧бứfes wurben nidjt unbedeuttende Ergänzungen und

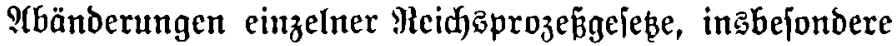

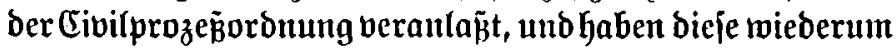

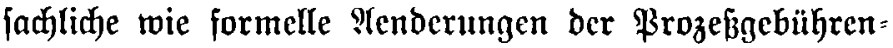
gejeke, wie fie in ber Faijung ber Befanutmad)ung bes

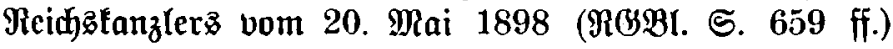
mitgetheilt wurben, zur nothwendigen Folge gehabt.

3roed bes vorliegenden handbuches ift mun, alle fïr ben Civil=, Sonturz= oder Etrafprozé in Betradyt tommenden Reid)z=(Sebiithrengefebe, mögen fie bie Be= bührenerhebung nur für bie Staatß̈taffe oder aud bie für bie Thätigfeit bon Beamten oder anderen ßerjonen betreffen, zu einem abgefflofienen Ganzen zu vereinen und jo bie Rürfe zwildfen ben reinen Tertaus̆gaben und ben Sommentaren dem Bedürfnifie entfpredfend aus= zufüllten.

In bemielben ift nad) Sid)tung des reidjlid zur Berfügung ftehenden Pluslegungsmaterialz bie vorherr= idjende Berifftspraxis unter befonberer Berürfichtigung ber Entidjeibungen bes Reidjageridjt ț und anderer höheren beutjđen Geridteghöje in zwar gebrängter, aber bod möglidjit vollitändiger Daritellung niebergelegt. Daß Buch foll im Bujammentyalte mit den nöthigen $\mathfrak{G} e=$ bührentabellen jowohl bem ßraftifer, meldjer fid mit

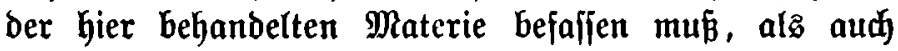


Demienigen, weldjer fic, in ber Grebührengejebgebung

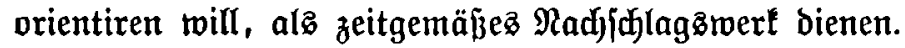

Möge ę find baher als ein nüb̧lidjer und braud)= barer Faührer erweifen, und möge bie $\mathfrak{M u ̈ h e , ~ b i e ~ d e r ~}$ Unterzeidjnetc biefer jeiner zweiten Mrbeit auf Dem (je=

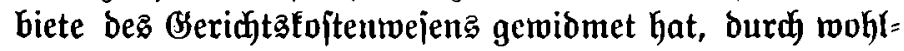
wollende $\mathfrak{A}$ jnahme und Beurtheilung feines $\mathfrak{B e r f e z}$ belohnt werben.

Znindeffeim, im Februar 1899.

fîn 